\title{
PENERAPAN ALGORITMA FISHER YATES SHUFFLE UNTUK APLIKASI UJIAN BERBASIS ANDROID
}

\author{
Victor Asih $^{1}$, Andi Saputra ${ }^{2}$, Ridho Taufiq Subagio ${ }^{3}$ \\ Universitas Catur Insan Cendekia \\ Jl. Kesambi 202, Kota Cirebon, Jawa Barat Tlp : (0231) 220250 \\ Email : victor.asih@cic.ac.id ${ }^{1}$, andsptraa18@gmail.com² ${ }^{2}$,ridho.taufiq@cic.ac.id ${ }^{3}$
}

\begin{abstract}
Abstrak
Pada era teknologi seperti saat sekarang ini, komputer memainkan peran yang semakin meningkat dalam berbagai bidang sisi kehidupan manusia. Penerapan teknologi informasi sudah sangat banyak digunakan dalam berbagai bidang, salah satunya dalam bidang pendidikan. Teknologi informasi sudah berkembang secara cepat dan bidang pendidikan turut mengalami peningkatan dalam hal kualitas, kecepatan, kepraktisan dan juga kemudahan. Di beberapa perguruan tinggi masih terdapat ujian semester yaitu ujian tengah semester dan ujian akhir semester dan penerapan ujian semester masih dilakukan secara konvensional yaitu dengan menggunakan kertas dan alat tulis sebagai penunjang ujian semester. Hal tersebut menyebabkan memakan banyak biaya dan waktu. Biaya dalam hal ini pihak kampus banyak mengeluarkan dana untuk membuat soal ujian dan memfotocopy soal ujian tersebut serta harus mengeluarkan dana tambahan untuk lembar jawaban. Dan waktu dalam hal ini adalah lamanya tahap proses mengkoreksi jawaban untuk menghasilkan sebuah nilai dari setiap mahasiswa/mahasiswi. Dengan dibuatnya Aplikasi Ujian ini diharapkan dapat mempermudah dosen dalam membuat soal, mengoreksi jawaban, mempermudah mahasiswa dalam melaksanakan ujian secara online.
\end{abstract}

Kata Kunci : Teknologi informasi, Ujian, Aplikasi.

\begin{abstract}
In the technological era as it is today, computers play an increasingly increasing role in various areas of the side of human life. The application of information technology has been very widely used in various fields, one of which is in the field of education. Information technology has developed rapidly and the field of education has also increased in terms of quality, speed, practicality and also convenience. In some universities there are still semester exams namely midterm and final semester exams and the application of semester exams is still carried out conventionally using paper and stationery to support the semester exams. This causes a lot of cost and time consuming. Costs in this case the campus spent a lot of money to make exam questions and photocopy the exam questions and have to spend additional funds for answer sheets. And time in this case is the length of the process of correcting the answers to produce a value from each student. The application of this exam is expected to make it easier for lecturers to make questions, correct answers, make it easier for students to carry out examinations online.
\end{abstract}

Keywords: information technology, exams, applications.

\section{PENDAHULUAN}

\subsection{Latar Belakang Masalah}

Pada era teknologi seperti saat sekarang ini, komputer memainkan peran yang semakin meningkat dalam berbagai bidang sisi kehidupan manusia. Penerapan teknologi informasi sudah sangat banyak digunakan dalam berbagai bidang, salah satunya dalam bidang pendidikan. Teknologi informasi sudah berkembang secara cepat dan bidang pendidikan turut mengalami peningkatan dalam hal kualitas, kecepatan, kepraktisan dan juga kemudahan. Penerapan teknologi informasi dalam bidang pendidikan sangat banyak, seperti pendaftaran online, raport online, krs online dan lain sebagainya. Saat ini ujian online sudah banyak 
digunakan diberbagai sekolah atau perguruan tinggi. Ada yang menggunakan ujian online untuk ujian masuk ke sekolah atau perguruan tinggi dan ada pula yang menggunakannya sebagai ujian semester. Ujian semester digunakan sebagai kegiatan untuk mengetahui hasil belajar mahasiswa dalam semester tersebut. Terdapat beberapa penelitian sejenis yang dilakukan sebelumnya, yang pertama yaitu jurnal yang ditulis oleh (Saraswati \& Putra, 2018). Dalam penelitian tersebut, sistem ujian yang digunakan masih menggunakan komputer yang mempunyai keterbatasan tempat untuk melakukan ujian yang berbasis web. Yang kedua yaitu jurnal yang ditulis oleh (Julianti \& Silalahi, 2015). Dalam penelitian tersebut, soal ujian yang dipakai di sistem ujian online hanya soal pilihan ganda atau multiple choice.

Penerapan ujian yang masih dilakukan secara konvensional yaitu dengan menggunakan kertas dan alat tulis sebagai penunjang ujian semester. Dalam menghasilkan sebuah nilai dari sebuah ujian masih sangat lama, karena dosen harus mengoreksi satu per satu jawaban dari setiap mahasiswa/mahasiswi di setiap mata kuliahnya. Hal tersebut menyebabkan memakan banyak biaya dan waktu. Biaya dalam hal ini pihak kampus banyak mengeluarkan dana untuk membuat soal ujian dan memfotocopy soal ujian tersebut serta harus mengeluarkan dana tambahan untuk lembar jawaban. Dan waktu dalam hal ini adalah lamanya tahap proses mengkoreksi jawaban untuk menghasilkan sebuah nilai dari setiap mahasiswa/mahasiswi. Maka dari itu diperlukan sebuah sistem ujian online yang bisa mempermudah dosen dalam membuat soal dan jawaban, mempermudah mahasiswa dalam melaksanakan ujian secara online. Berdasarkan latar belakang masalah tersebut maka penulis melakukan penilitian dengan judul "Penerapan Algoritma Fisher Yates Shuffle Untuk Aplikasi Ujian Berbasis Android" yang diharapkan dapat menjadi solusi dari masalah yang ada.

\subsection{Identifikasi Masalah}

Berdasarkan Latar Belakang Masalah di atas, maka penulis dapat menguraikan identifikasi masalah sebagai berikut :

1. Ujian semester yang masih konvensional atau masih menggunakan kertas sebagai soal dan jawaban tentu mengeluarkan banyak biaya.

2. Bagaimana membuat aplikasi ujian online yang dapat mempermudah dosen dalam membuat soal, jawaban dan menampilkan hasil ujian?

3. Bagaimana membuat aplikasi ujian online yang bisa dapat mempermudah mahasiswa?

\subsection{Batasan Masalah}

Beberapa batasan masalah dilakukan dengan prosedur-prosedur sebagai berikut :

1. Aplikasi ini memiliki dua jenis soal yaitu Essay dan Pilihan Ganda.

2. Aplikasi ini mencakup Ujian Tengah Semester (UTS) dan Ujian Akhir Semester (UAS).

3. Aplikasi ini dibuat hanya untuk soal yang mempunyai jawaban berupa teks.

4. Untuk pengacakan token dalam aplikasi ini menggunakan Algoritma Fisher-Yates Shuffle.

5. Yang dapat mengakses sistem ini adalah :

Web :

a. Biro Administrasi Akademik dan Kemahasiswaan (BAAK)

1) Mengelola data dosen.

2) Mengelola data mata kuliah.

3) Mengelola data mahasiswa.

4) Mengelola data jurusan.

b. Dosen

1) Membuat soal \& jawaban ujian.

2) Membuat token untuk setiap mata kuliah yang akan diujikan.

3) Mengoreksi jawaban ujian.

Android :

a. Mahasiswa

1) Memasukan token untuk memulai ujian.

2) Mengerjakan ujian sampai waktu yang sudah ditentukan.

\subsection{Tujuan}

Adapun yang menjadi tujuan dari aplikasi yang akan dibuat adalah :

1. Aplikasi ini dibuat untuk mengurangi penggunaan kertas dan mengurangi biaya dalam kegiatan ujian semester. 
2. Aplikasi ini dibuat untuk mempermudah dosen dalam membuat soal dan jawaban serta menampilkan hasil ujian.

3. Aplikasi ini dibuat untuk mempermudah mahasiswa dalam melaksanakan ujian.

\section{KAJIAN PUSTAKA}

\subsection{Rancang Bangun}

Perancangan merupakan salah satu hal yang penting dalam membuat program. Adapun tujuan dari perancangan ialah untuk memberi gambaran yang jelas lengkap kepada pemrogram dan ahli teknik yang terlibat. Perancangan harus berguna dan mudah dipahami sehingga mudah digunakan. Perancangan adalah sebuah proses untuk mendefinisikan sesuatu yang akan dikerjakan dengan menggunakan teknik yang bervariasi serta di dalamnya melibatkan deskripsi mengenai arsitektur serta detail komponen dan juga keterbatasan yang akan dialami dalam proses pengerjaanya [1]. Pembangunan atau bangun sistem adalah kegiatan menciptakan sistem baru maupun mengganti atau memperbaiki sistem yang telah ada secara keseluruhan. Jadi dapat disimpulkan bahwa rancang bangun adalah penggambaran, perencanaan, dan pembuatan sketsa atau pengaturan dari beberapa elemen yang terpisah kedalam suatu kesatuan yang utuh dan berfungsi. Dengan demikian pengertian rancang bangun merupakan kegiatan menerjamahkan hasil analisa ke dalam bentuk paket perangkat lunak kemudian menciptakan sistem tersebut atau memperbaiki sistem yang sudah ada [1].

\subsection{Aplikasi}

Perangkat lunak aplikasi adalah suatu subkelas perangkat lunak komputer yang memanfaatkan kemampuan komputer langsung untuk melakukan suatu tugas yang diinginkan pengguna. Biasanya dibandingkan dengan perangkat lunak sistem yang mengintegrasikan berbagai kemampuan komputer, tapi tidak secara langsung menerapkan kemampuan tersebut untuk mengerjakan suatu tugas yang menguntungkan pengguna [2].

\subsection{Ujian}

Menurut Kamus Besar Bahasa Indonesia (KBBI), pengertian ujian yaitu sesuatu yang dipakai untuk menguji mutu sesuatu (kepandaian, kemampuan, hasil belajar, dan sebagainya). Terdapat dua ujian dalam bidang pendidikan yaitu Ujian Tengah Semester (UTS) dan Ujian Akhir Semester (UAS). Ujian Tengah Semester (UTS) yaitu ujian yang diberikan di perguruan tinggi pada waktu pertengahan perkuliahan dalam setiap semester. Ujian Akhir Semester (UAS) yaitu ujian yang diberikan di perguruan tinggi pada waktu perkuliahan berakhir dalam setiap semester [2].

\subsection{Algoritma}

Algoritma merupakan fondasi yang harus dipahami atau dikuasai oleh seseorang yang akan menyelesaikan suatu masalah dengan komputer, dalam hal ini dengan membuat program. Algoritma berasal dari kata al-kwarizmi yang terdapat di buku Abu Ja'far Muhammad Ibnu Musa Al-Kwarizmi, seorang ahli Matematika dari Persia dengan judul bukunya "Aljabar wal Muqabala". Dalam beberapa bukunya terdapat beberapa definisi algoritma. Dalam buku ini, definisi algoritma adalah susunan langkah penyelesaian suatu masalah secara sistematika dan logis. Terdapat dua kata yang menjadi perhatian dalam definisi ini, yaitu sistematis dan logis [4].

\subsection{Fisher Yates Shuffle}

Algoritma Fisher-Yates (diambil dari nama Ronal Fisher dan Frank Yates) atau dikenal juga dengan nama Knuth Shuffle (diambil dari nama Donald Knuth), adalah sebuah algoritma yang menghasilkan permutasi acak dari suatu himpunan terhingga, dengan kata lain untuk mengacak suatu himpunan tersebut. Jika di implementasikan dengan benar maka hasil dari algoritma ini tidak akan berat sebelah sehingga setiap permutasi memiliki kemungkinan yang sama. Algoritma Fisher Yates dianggap oleh banyak orang sebagai metode untuk menghasilkan permutasi acak dari satu set terbatas. Algoritma Fisher Yates yang pertama diusulkan pada tahun 1938 dan dikaji pada tahun 1948 dengan versi modern yang disajikan dalam sebuah varian. Algoritma diterbitkan oleh Wilson pada tahun 2004 bernama “Algoritma Santtolo". Dalam memvalidasi Fisher Yates Shuffle, sebuah analisis statistik dari algoritma menggunakan analisis frekuensi 
yang disampaikan dalam sebuah kesimpulan-kesimpulan analisa yang menarik tentang kecepatan algoritma ini [5].

\section{PERANCANGAN SISTEM}

3.1. Algoritma Fisher Yates Shuffle

Penerapan algoritma Fisher Yates Shuffle untuk mengacak token ujian.

\subsubsection{Flowchart Algoritma Fisher Yates Shuffle}

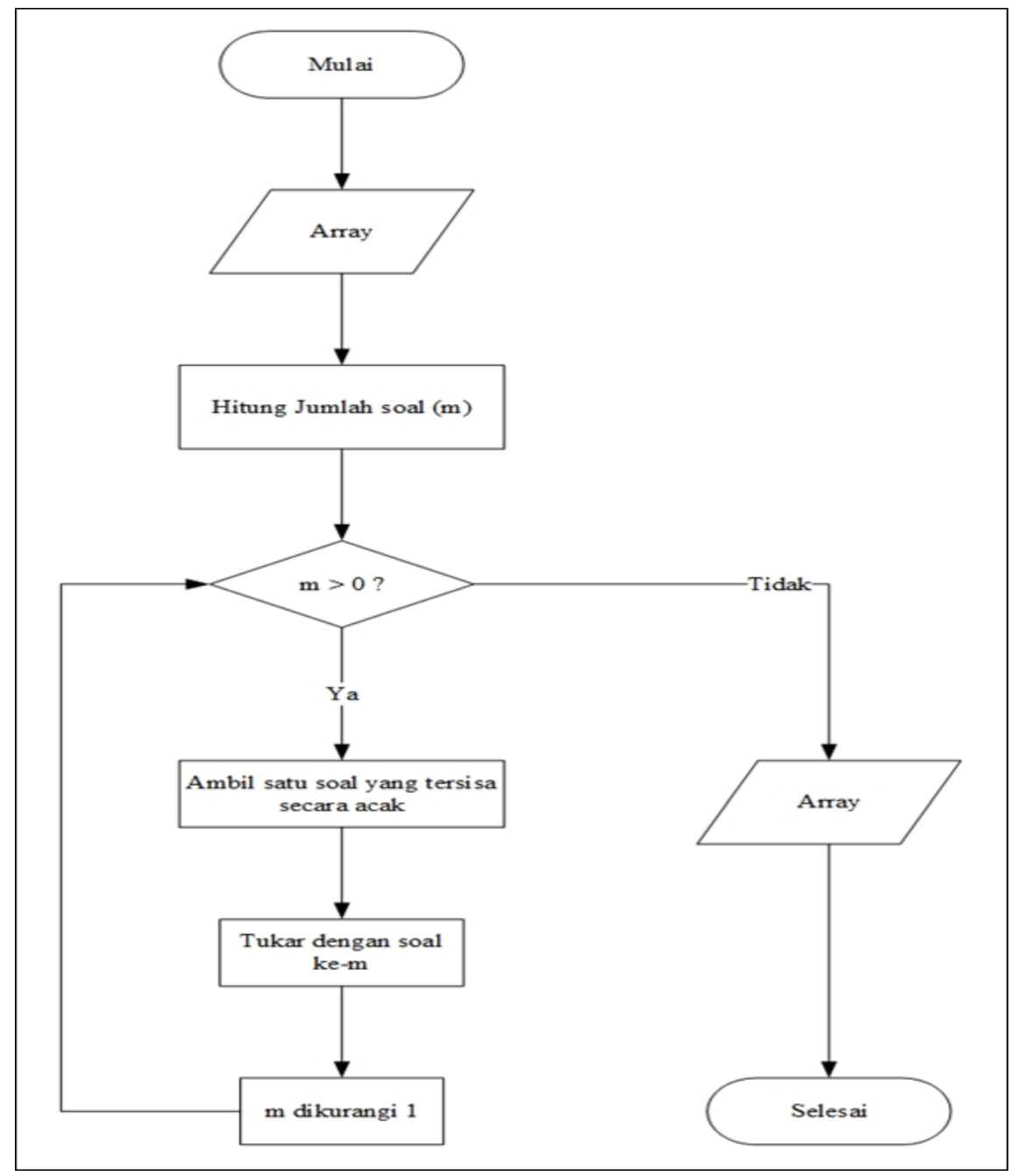

Gambar 1. Flowchart Algoritma Fisher Yates Shuffle

\section{Keterangan :}

1. Hitung jumlah token yang ada.

2. Jika jumlah token lebih dari 0 , maka

3. Ambil satu token yang tersisa secara acak.

4. Tukar dengan token ke- $\mathrm{m}$ (m yaitu batas jumlah token, misalkan 20 isi token berarti tukar ke isi token nomor 20).

5. Lalu jumlah token dikurangi 1 .

6. Pengulangan akan terus berlanjut sampai isi token yang tersisa / belum diacak sudah habis.

7. Jika jumlah isi token dibawah 0 maka tidak akan melakukan pencacakan.

8. Selesai. 


\subsubsection{Implementasi Algoritma Fisher Yates Shuffle}

Algoritma Fisher Yates Shuffle diimplementasikan dengan alur sebagai berikut :

1. Dosen membuat soal ujian.

2. Dosen membuat jawaban dari setiap soal ujian.

3. Pembuatan ujian dengan membuat jadwal ujian dan pembuatan token otomatis.

4. Menampilkan hasil token ujian yang sudah diacak.

\subsubsection{Contoh Perhitungan Algoritma Fisher Yates Shuffle}

Didalam Aplikasi Ujian Online misalkan terdapat 8 token ujian yang akan diacak. Maka didapatkan panjang array $(\mathrm{m})=8$.

Langkah-langkah pengacakan token ujian menggunakan Fisher Yates Shuffle adalah sebagai berikut :

1. Ambil satu isi token secara acak (i). Nilai i yang boleh diambil yaitu nilai yang masih berada di Range 18.

2. Nilai i yang diambil ditukarkan dengan token ke m(nilai m yaitu batas jumlah token). Nilai m yaitu 8 . Posisi nilai i yang sudah diambil secara acak ditukar nilai m yaitu 8 .

3. Pengulangan akan dilakukan sampai nilai yang akan diacak sudah tidak ada.

Berikut adalah tabel contoh pengacakan menggunakan Algoritma Fisher Yates Shuffle dengan jumlah array $(\mathrm{m})=8$.

Tabel 1. Contoh Pengacakan Algoritma Fisher Yates Shuffle

\begin{tabular}{|c|c|c|c|c|}
\hline Step & Range & Roll & Scratch & Result \\
\hline \multicolumn{2}{|l|}{} & & $\mathbf{1 2 3 4 5 6 7 8}$ & \\
\hline 1 & $1-8$ & 4 & 1238567 & 4 \\
\hline 2 & $1-7$ & 6 & 123857 & 64 \\
\hline 3 & $1-6$ & 2 & 17385 & 264 \\
\hline 4 & $1-5$ & 7 & 1538 & 7264 \\
\hline 5 & $1-4$ & 1 & 853 & 17264 \\
\hline 6 & $1-3$ & 3 & 85 & 5317264 \\
\hline 7 & $1-2$ & 5 & 8 & $\mathbf{8 5 3 1 7 2 6 4}$ \\
\hline
\end{tabular}

Keterangan :

1. Step yaitu urutan langkah dalam proses mengacak,

2. Range yaitu jumlah angka yang belum terpilih,

3. Roll adalah angka acak yang terpilih,

4. Scratch adalah daftar angka yang belum terpilih,

5. Result adalah hasil permutasi yang akan didapatkan. 


\subsection{Use Case Diagram Aktor Dosen}

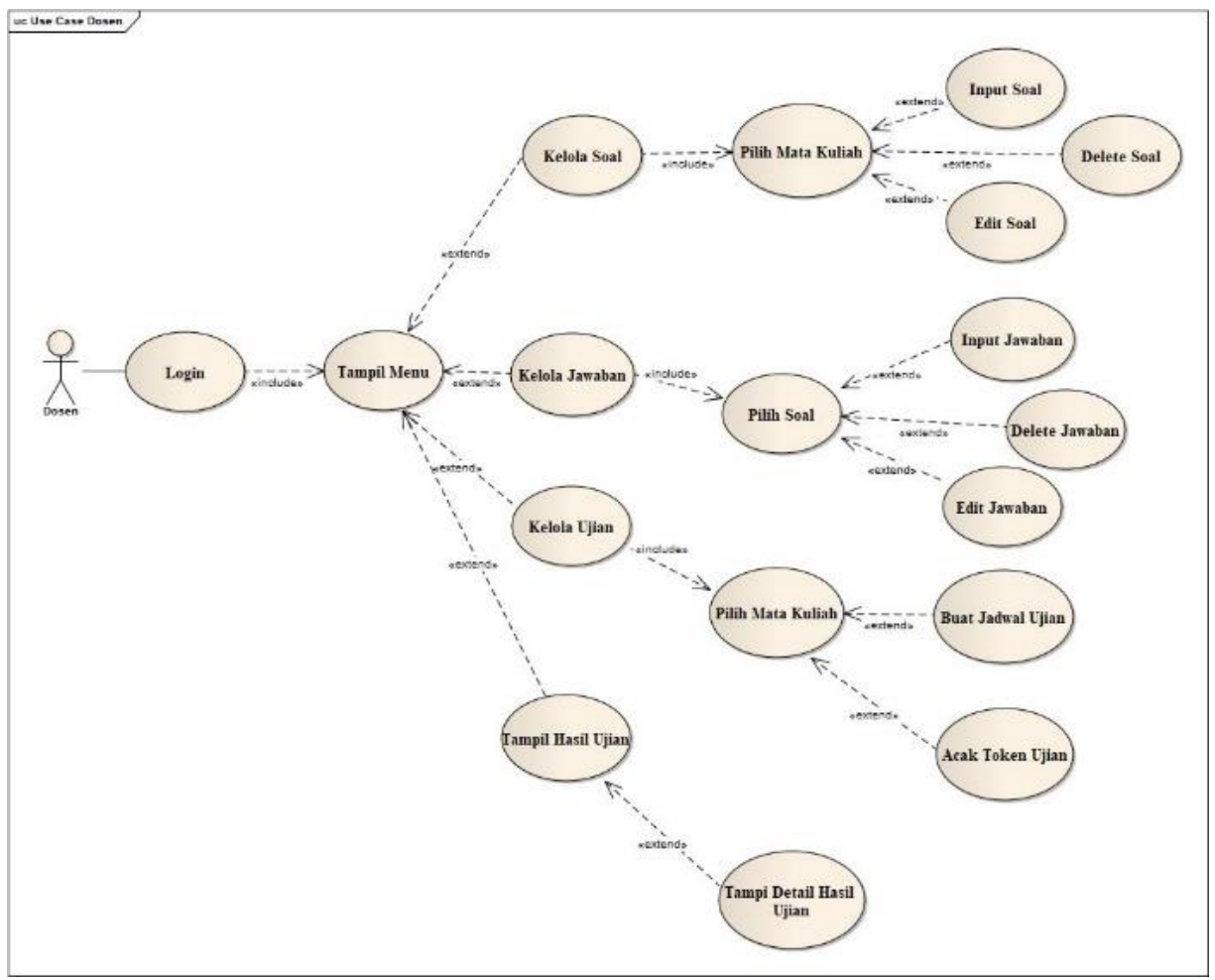

Gambar 2. Use Case Diagram Aktor Dosen

3.3. Use Case Diagram Aktor BAAK

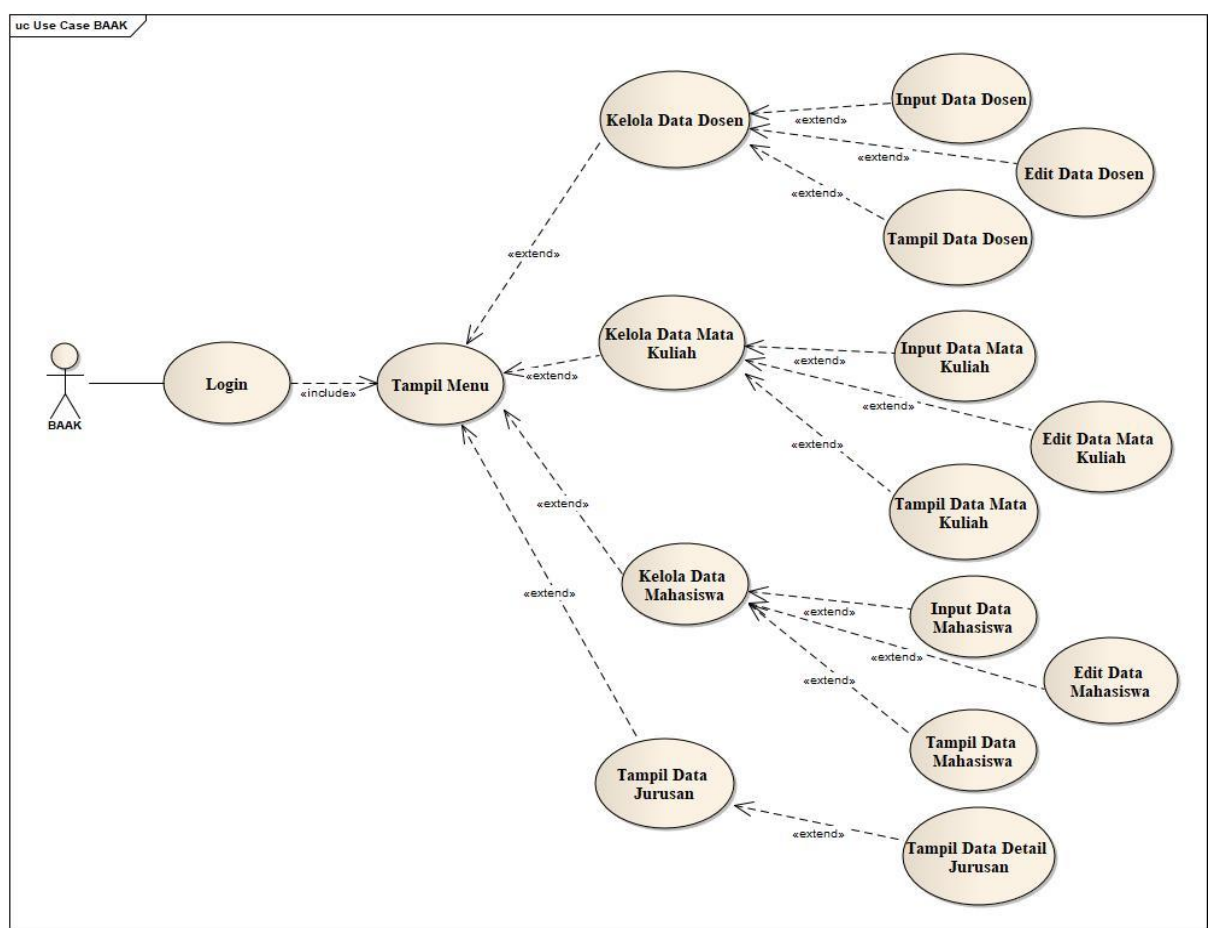

Gambar 3. Use Case Diagram Aktor BAAK

Penerapan Algoritma Fisher Yates Shuffle untuk Aplikasi Ujian Berbasis Android (Victor Asih, Andi Saputra, Ridho Taufiq Subagio) 
3.4. Use Case Diagram Aktor Mahasiswa

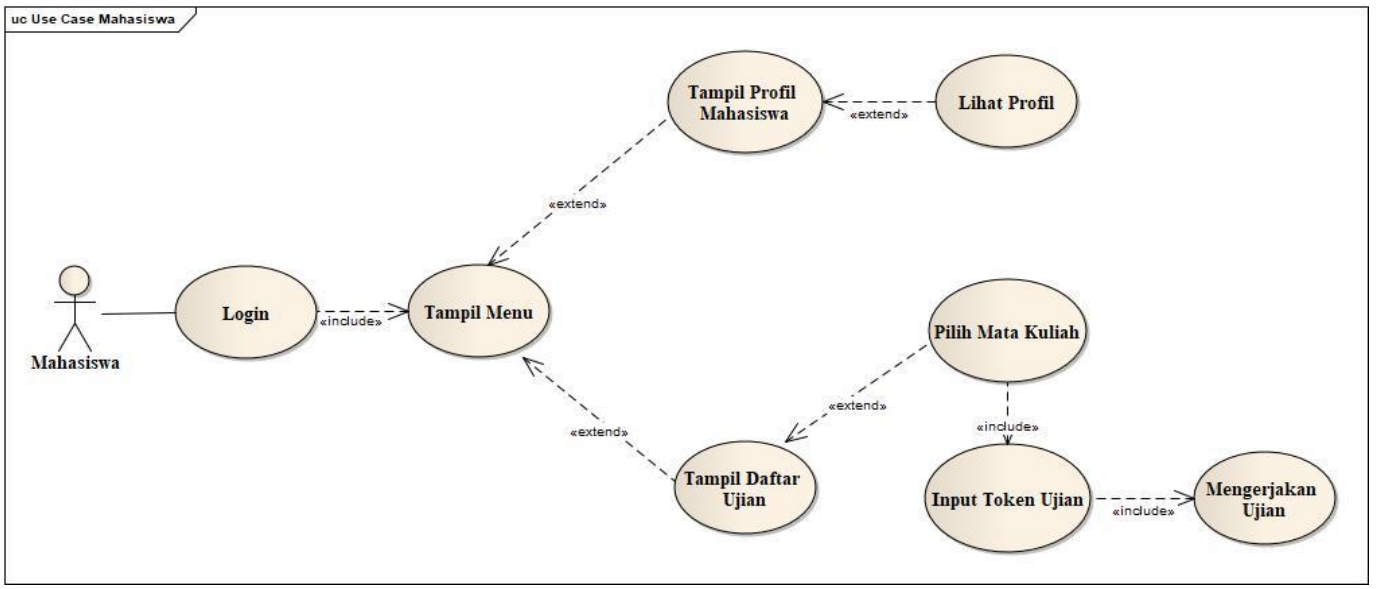

Gambar 4. Use Case Diagram Aktor Mahasiswa

3.5. Activity Diagram Aktor BAAK

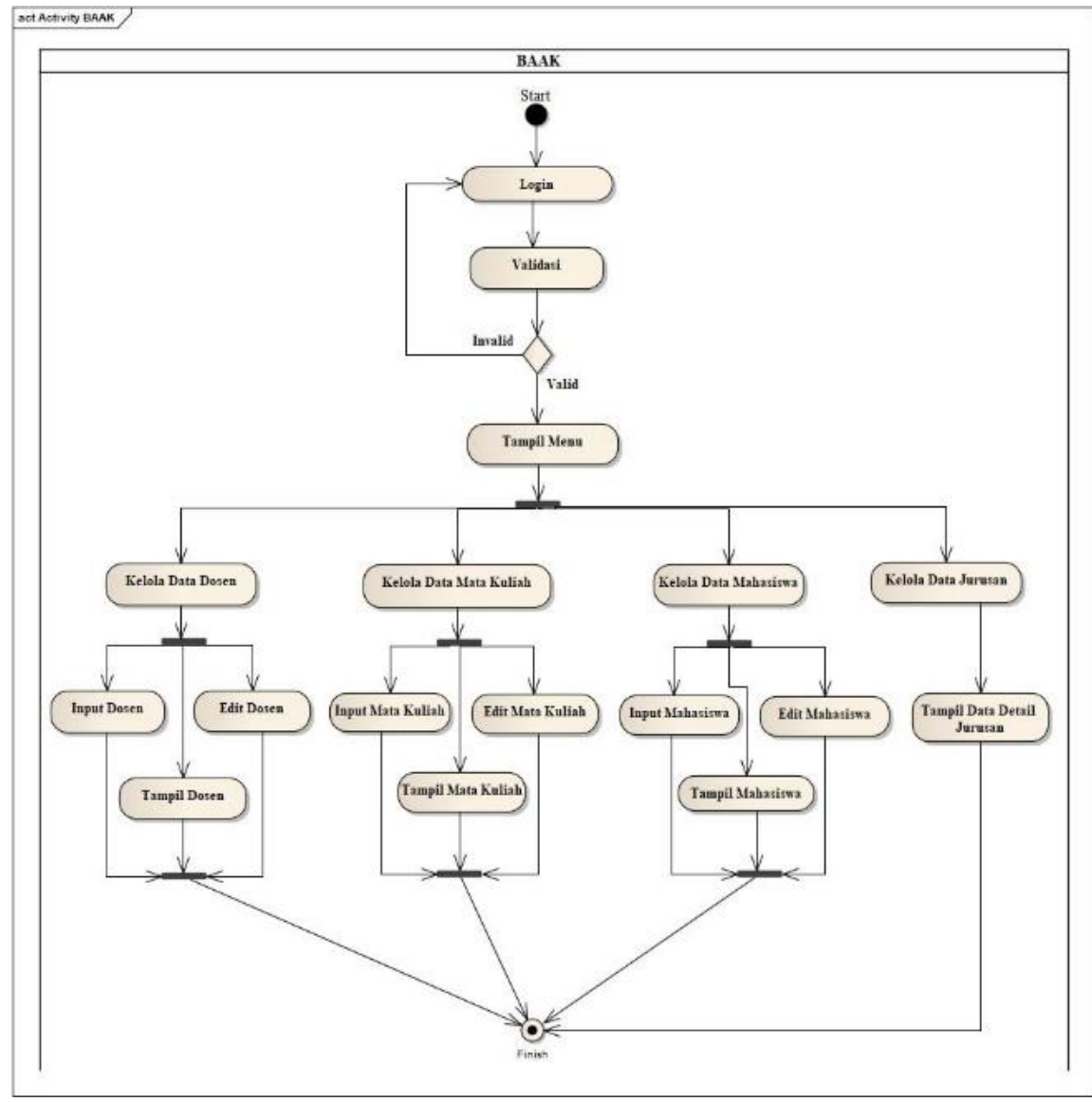

Gambar 5. Activity Diagram Aktor BAAK 
3.6. Activity Diagram Aktor BAAK

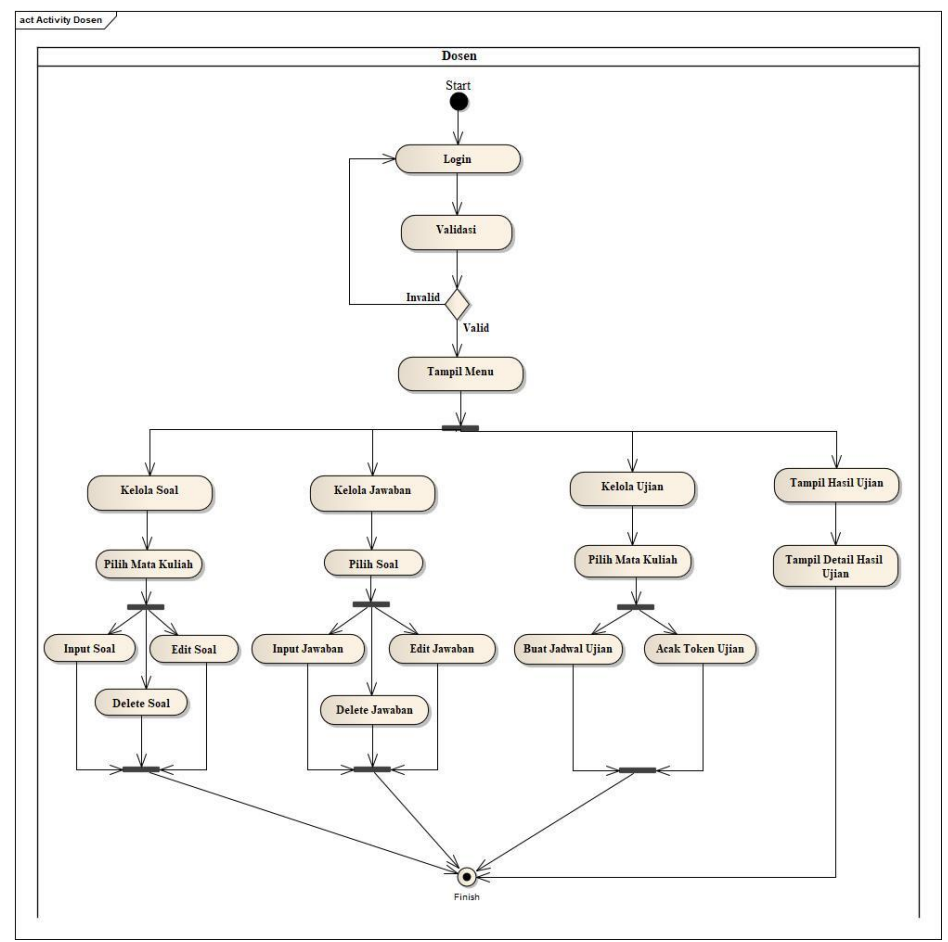

Gambar 6. Activity Diagram Aktor Dosen

3.7. Activity Diagram Aktor Mahasiswa

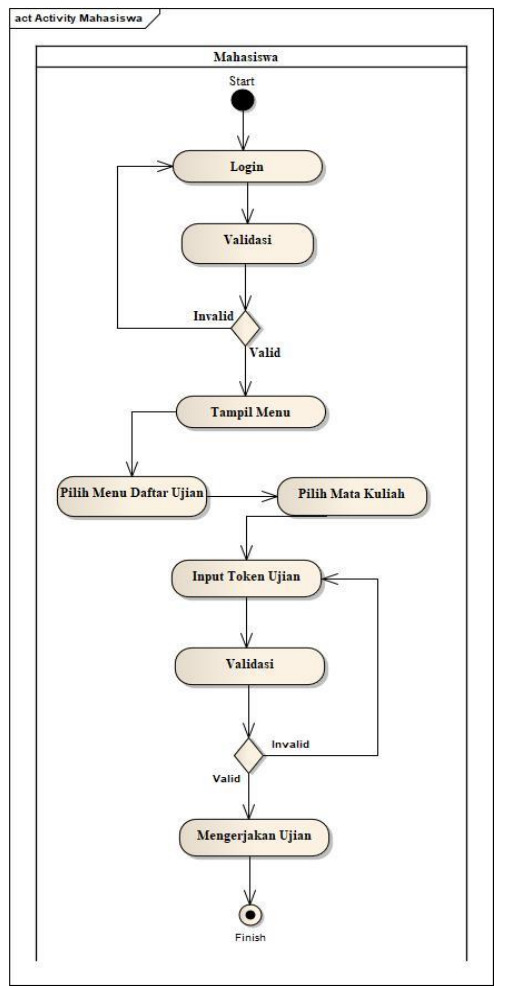

Gambar 7. Activity Diagram Aktor Mahasiswa 
3.8. Class Diagram

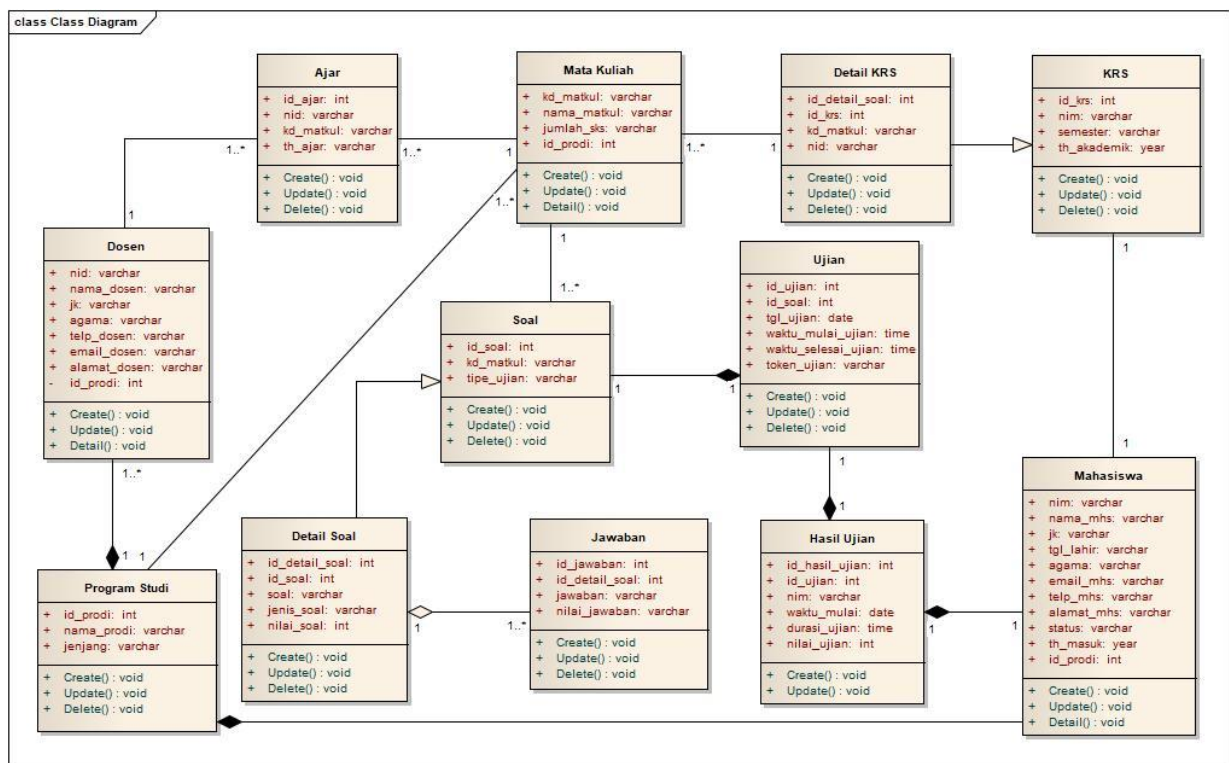

Gambar 8. Class Diagram

\section{IMPLEMENTASI SISTEM}

\subsection{Tampilan Android Mahasiswa}

Halaman ini menampilkan form login untuk setiap mahasiswa yang akan masuk ke dalam aplikasi.

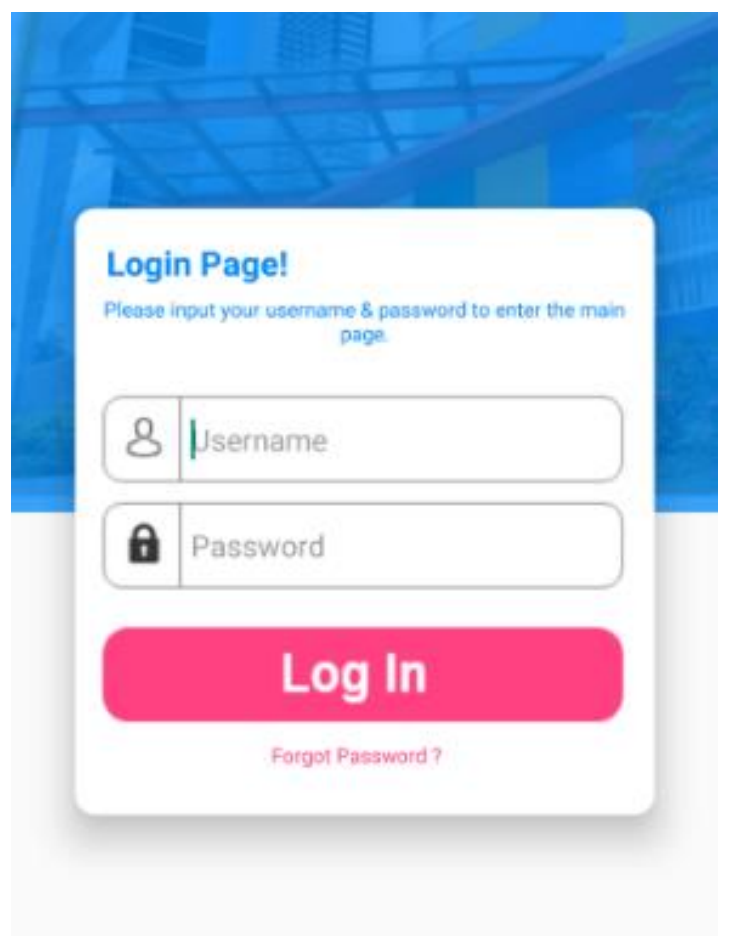

Gambar 9. Tampilan Android Mahasiswa 


\subsection{Tampilan Halaman Home}

Halaman ini menampilkan tampilan awal ketika sebuah mahasiswa berhasil masuk ke dalam aplikasi.

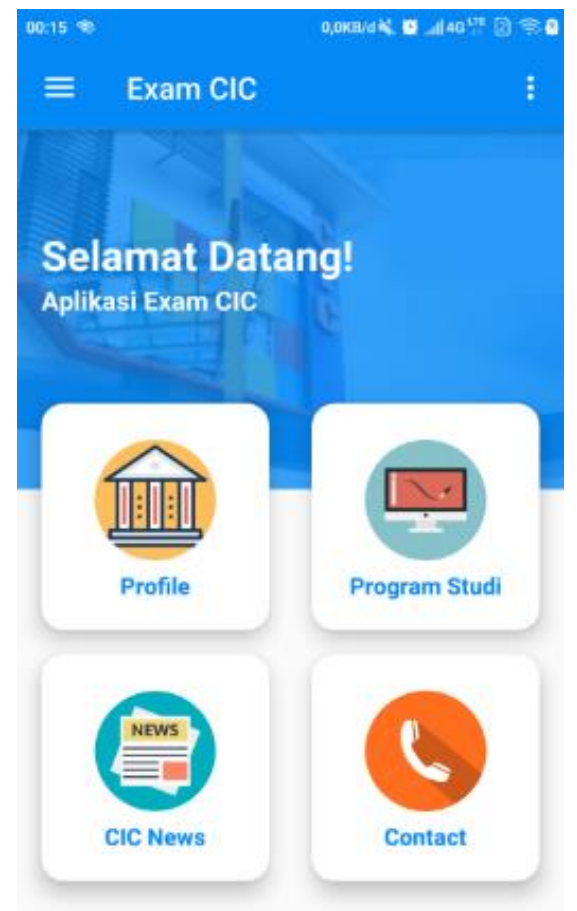

Gambar 10. Tampilan Menu Halaman Home

\subsection{Tampilan Halaman Profil}

Pada halaman ini menampilkan data-data profil singkat dari setiap mahasiswa.

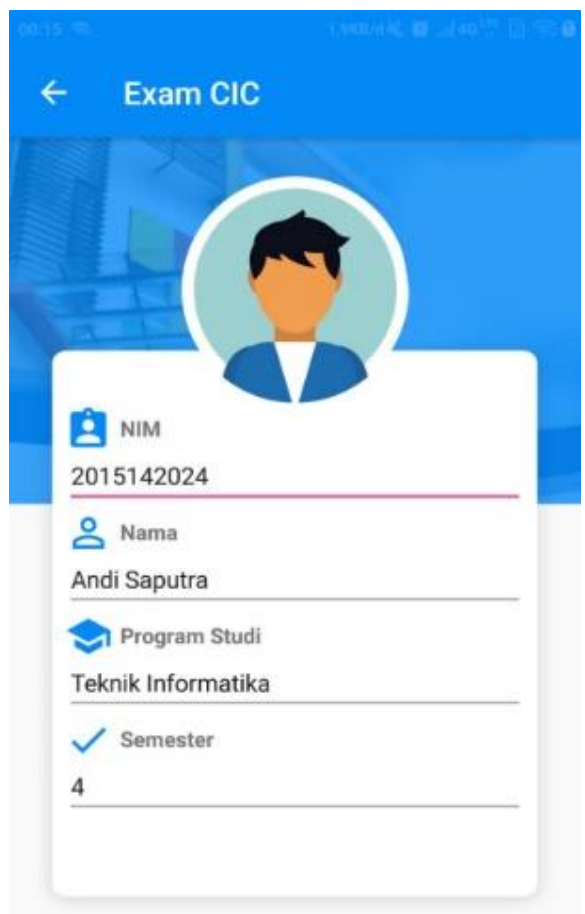

Gambar 11. Tampilan Menu Profil 


\subsection{Tampilan Halaman Daftar Ujian}

Pada halaman ini menampilkan data-data daftar ujian yang akan dilaksanakan yang terdapat nama mata kuliah dan jadwal ujian.

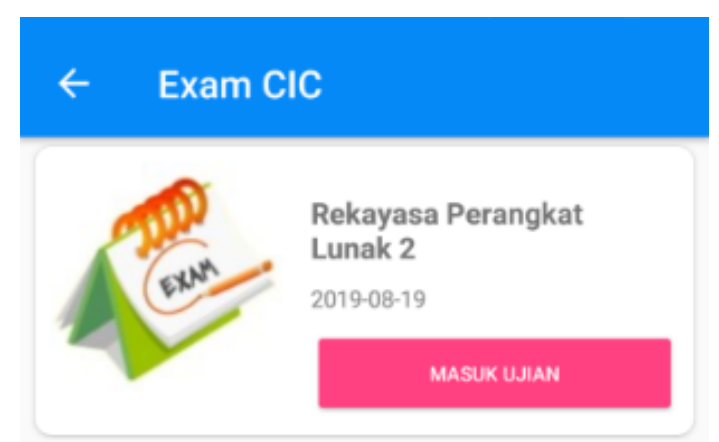

Gambar 12. Tampilan Menu Daftar Ujian

\subsection{Tampilan Halaman Form Token Ujian}

Pada halaman ini menampilkan sebuah form token ujian untuk masuk ke halaman ujian. Setiap mahasiswa akan diberikan token ujian.

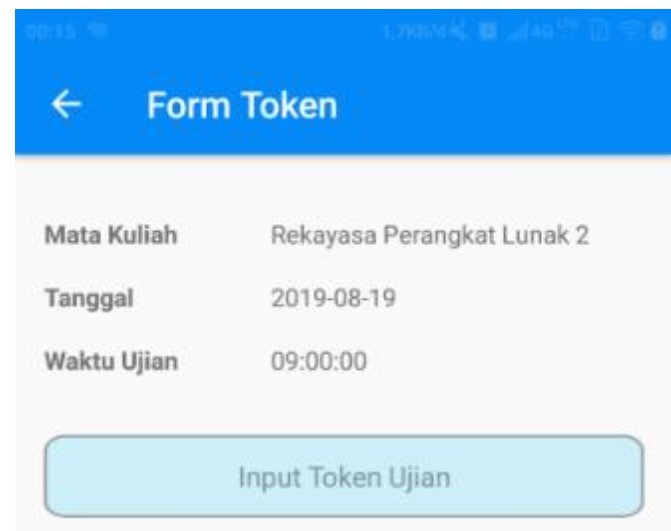

\section{MULAI UJIAN}

Gambar 13. Tampilan Halaman Form Token Ujian 


\subsection{Tampilan Halaman Ujian}

Pada halaman ini digunakan untuk menampilkan sebuah ujian yang berisikan soal-soal, jawaban dan waktu ujian.

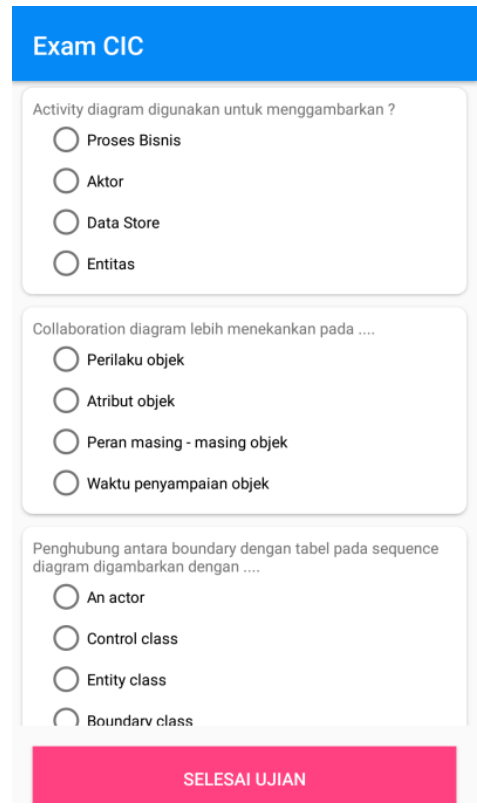

Gambar 14. Tampilan Halaman Ujian

\section{KESIMPULAN DAN SARAN}

\subsection{Kesimpulan}

Berdasarkan masalah dan pembahasan yang telah diuraikan diatas maka dapat diambil kesimpulan yaitu:

1. Aplikasi ini dapat dijadikan sebagai cara baru sebuah ujian yang akan menghemat biaya, waktu dan tempat.

2. Aplikasi ini dapat digunakan oleh dosen dalam hal membuat soal dan jawaban dengan mudah dan cepat.

3. Aplikasi ini dapat digunakan oleh mahasiswa untuk melaksanakan ujian dengan mudah dan nyaman.

\subsection{Saran}

Untuk pengembangan aplikasi ini saran yang diberikan yaitu :

1. Pembuatan soal bisa dilakukan dengan cara mengupload file dari word agar soal lebih bervariasi.

2. Pembuatan token ujian dirubah menjadi untuk setiap mahasiswa agar ujian lebih baik lagi dan tidak ada kecurangan.

3. Untuk halaman ujian bisa diperbaiki agar tampilan bisa memuat lebih luas dan soal bisa ditampilkan satu halaman satu soal.

4. Untuk soal ujian sebaiknya tetap di acak, menggunakan algoritma atau pun tidak.

\section{DAFTAR PUSTAKA}

[1] Muh. Farhan Syukroni, Rancang Bangun Knowledge Management System Berbasis Web pada Madrasah Mualimin Al-Islamiyah Uteran Geger Madiun. Ponorogo, 2017.

[2] Nazrudin Safaat H. Pemograman Aplikasi Mobile Smartphone dan Tablet PC Berbasis Android. Bandung: Informatika, 2012.

[3] https://kbbi.web.id/uji

[4] Sitorus Lamhot. Algoritma dan Pemrograman. Yogyakarta: Penerbit ANDI, 2015.

[5] Hasan Arief Mhd. Implementasi Algoritma Fisher-Yates Untuk Mengacak Soal Ujian Online Penerimaan Mahasiswa Baru. Riau, 2017. 